\title{
Hydroxyurea treatment inhibits proliferation of Cryptococcus neoformans in mice
}

\author{
Kaushlendra Tripathi ${ }^{1}$, Visesato Mor ${ }^{1}$, Narendra K. Bairwa ${ }^{1}$, Maurizio Del Poeta ${ }^{1,2,3,4}$ * \\ and Bidyut K. Mohanty ${ }^{1}$ *
}

${ }^{1}$ Department of Biochemistry and Molecular Biology, Medical University of South Carolina, Charleston, SC, USA

${ }^{2}$ Department of Microbiology and Immunology, Medical University of South Carolina, Charleston, SC, USA

${ }^{3}$ Department of Craniofacial Biology, Medical University of South Carolina, Charleston, SC, USA

${ }^{4}$ Division of Infectious Diseases, Medical University of South Carolina, Charleston, SC, USA

\section{Edited by:}

Joshua D. Nosanchuk, Albert Einstein College of Medicine, USA

\section{Reviewed by:}

Andrew Alspaugh, Duke University

School of Medicine, USA

John C. Panepinto, State University of

New York at Buffalo, USA

*Correspondence:

Maurizio Del Poeta and Bidyut K. Mohanty, Department of

Biochemistry and Molecular Biology, Medical University of South Carolina, 173 Ashley Avenue, Charleston, SC 29412, USA. e-mail:

delpoeta@musc.edu;

mohanty@musc.edu
The fungal pathogen Cryptococcus neoformans $(\mathrm{Cn})$ is a serious threat to immunocompromised individuals, especially for HIV patients who develop meningoencephalitis. For effective cryptococcal treatment, novel antifungal drugs or innovative combination therapies are needed. Recently, sphingolipids have emerged as important bioactive molecules in the regulation of microbial pathogenesis. Previously we reported that the sphingolipid pathway gene, ISC1, which is responsible for ceramide production, is a major virulence factor in $\mathrm{Cn}$ infection. Here we report our studies of the role of ISC1 during genotoxic stress induced by the antineoplastic hydroxyurea (HU) and methyl methanesulfonate (MMS), which affect DNA replication and genome integrity. We observed that $C n$ cells lacking ISC1 are highly sensitive to $\mathrm{HU}$ and MMS in a rich culture medium. HU affected cell division of $\mathrm{Cn}$ cells lacking the ISC1 gene, resulting in cell clusters. Cn ISC1, when expressed in a Saccharomyces cerevisiae $(S C)$ strain lacking its own ISC1 gene, restored HU resistance. In macrophagelike cells, although $\mathrm{HU}$ affected the proliferation of wild type (WT) Cn cells by $50 \%$ at the concentration tested, $\mathrm{HU}$ completely inhibited $\mathrm{Cn}$ isc1 $1 \Delta$ cell proliferation. Interestingly, our preliminary data show that mice infected with WT or $C n$ isc1 $1 \Delta$ cells and subsequently treated with HU had longer lifespans than untreated, infected control mice. Our work suggests that the sphingolipid pathway gene, $I S C 1$, is a likely target for combination therapy with traditional drugs such as $\mathrm{HU}$.

Keywords: Cryptococcus, ISC1, hydroxyurea, morphology

\section{INTRODUCTION}

Cryptococcus spp. are environmental fungal pathogens afflicting immunocompromised patients as well as immunocompetent individuals, causing life-threatening meningoencephalitis (Idnurm et al., 2005; Jarvis et al., 2008; Dadachova and Casadevall, 2011; Del Poeta and Casadevall, 2011; Kronstad etal., 2011; Kozubowski and Heitman, 2012). Cryptococcus causes approximately one million annual cases of meningoencephalitis globally among AIDS patients, leading to nearly 625,000 deaths (Park etal., 2009). Despite major developments in HIV treatment Cryptococcus infection still remains a major threat to AIDS patients, especially in sub-Saharan Africa (Warkentien and Crum-Cianflone, 2010).

Cryptococcus neoformans $(\mathrm{Cn})$ is a ubiquitous fungus, found in tree hollows and pigeon droppings. It is present in the environment and in human hosts predominantly in the yeast form; however, $\mathrm{Cn}$ can assume hyphal and other shapes depending upon its life cycle state or environmental influences (Zaragoza et al., 2010; Kronstad et al., 2011; Kozubowski and Heitman, 2012). Pathogenic Cn infection initiates upon the inhalation of infectious $\mathrm{Cn}$ particles, which initially disseminate to the lungs and subsequently to the central nervous system via the circulation if the host's immune response does not control fungal proliferation within the lung
(Kronstad et al., 2011). An intracellular facultative pathogen, $\mathrm{Cn}$ can grow and replicate within the phagolysosome of phagocytic cells, such as alveolar macrophages (AMs) and it can also grow in extracellular spaces, such as within the alveoli or in the bloodstream (Feldmesser et al., 2000; Goldman et al., 2000; Levitz, 2001; Steenbergen et al., 2001; Shea et al., 2006). Because the pathogen rapidly develops drug resistance (Morschhauser, 2010), and because the number of immunocompromised patients is increasing, there is a constant need for innovative and effective antifungal therapies.

Hydroxyurea (HU), an antineoplastic drug used for treatment of HIV, cancer, and myeloproliferative diseases (Kovacic, 2011) slows the progression of DNA replication machinery by reducing the cell's deoxyribonucleotide (dNTP) pool (Katou et al., 2003). HU treatment of the budding yeast Saccharomyces cerevisiae (Sc) results in DNA replication fork slowing, and the formation of a fork-protection complex to guard the cell's replication machinery, activating the replication checkpoint (Alcasabas et al., 2001; Katou et al., 2003; Zegerman and Diffley, 2003; Bando et al., 2009). In the absence of replication proteins, yeast cells become HU sensitive. Interestingly, in addition to DNA replication genes, $\sim 300$ genes from various other pathways have been shown to play role in resistance to HU toxicity and the absence of these genes gives 
rise to HU sensitivity (Chang et al., 2002; Hartman and Tippery, 2004; Parsons et al., 2004; Woolstencroft et al., 2006).

Recently, lipid signaling, especially sphingolipid metabolism, has gained recognition for its role in fungal pathogenesis (Shea and Del Poeta, 2006; Rhome and Del Poeta, 2010; Singh and Del Poeta, 2011). All yeast cells, including $C n$, produce inositolcontaining sphingolipids instead of choline-containing sphingolipids (e.g., sphingomyelin), and the deletion of the inositol sphingophospholipid phospholipase $\underline{C} 1$ (ISC1) gene in $S c$ (Sc $i s c 1 \Delta$ ) causes accumulation of inositol-containing sphingolipids (Sawai et al., 2000; Shea etal., 2006). Cn is a pathogenic yeast, and deletion of ISC1 renders it incapable of causing meningoencephalitis (Shea et al., 2006). Isc1 has been characterized in Sc (Sawai etal., 2000) and Cn (Henry etal., 2011) and in Leishmania (Zhang et al., 2009), indicating that this sphingolipid metabolizing enzyme has unique biochemical characteristics. The absence of the $I S C 1$ gene in $S c$ increases fungal sensitivity to $\mathrm{HU}$ and methyl methanesulfonate (MMS) accompanied by cell division arrest and morphological aberrations (Chang et al., 2002; Matmati etal., 2009; Tripathi et al., 2011). Here, we report our studies into the role of $\mathrm{Cn} \mathrm{ISCl}$ in the fungal resistance to $\mathrm{HU}$ and MMS and their specific effects on the virulence of the pathogenic fungus $C n$. We show that $C n$ cells lacking the $I S C 1$ gene are highly sensitive to HU and MMS and form cell clusters upon HU exposure. The absence of ISC1 in conjunction with HU treatment synergistically reduced $\mathrm{Cn}$ infection of macrophage-like cells and immunocompetent mice.

\section{MATERIALS AND METHODS STRAINS AND PLASMIDS}

Wild type (WT) Cn (var. grubii serotype A strain H99) and its isc $1 \Delta$ derivative were used in the current study and have been described previously (Shea et al., 2006; Henry et al., 2011). The Sc strain Jk9-3d a (MATa trp1 leu2-3 his4 ura3 ade2 rme1) and its isc $1 \Delta$ derivative were used and have been described previously (Matmati et al., 2009; Tripathi et al., 2011).

\section{EXPOSURE TO HU AND MMS}

YPD plates ( $1 \%$ yeast extract, $2 \%$ peptone, and $2 \%$ glucose plus $2 \%$ agar) containing appropriate concentrations of HU (Sigma; 0, $25,50,100$, and $200 \mathrm{mM}$ ) or MMS (Sigma; $0.033 \%$ ) were prepared and used within $48 \mathrm{~h}$. Overnight cultures were inoculated in fresh medium at $\mathrm{A}_{600}$ of 0.2 and grown at $30^{\circ} \mathrm{C}$. Log-phase cultures were adjusted to $\mathrm{A}_{600}$ of 0.4 before making 10 -fold serial dilutions and plate spotting $(2.5 \mu \mathrm{l})$. Plasmids pYES-Sc ISC1 and pYES-Cn ISC1 that express Sc ISC1 and Cn ISC1 genes respectively have been described previously (Henry et al., 2011). The two plasmids and a control vector were transformed into appropriate strains (WT and iscl $1 \Delta$ of $S c$ ) and plated on $\mathrm{SD} / \mathrm{Ura}^{-}$plates. Then, 10 -fold serial dilutions of log-phase liquid cultures in $\mathrm{SD} / \mathrm{Ura}^{-}$liquid medium were spotted on $\mathrm{SD} / \mathrm{Ura}^{-}$and $\mathrm{SD} / \mathrm{Ura}^{-} / \mathrm{HU}$ plates, and the plates were incubated at $30^{\circ} \mathrm{C}$, and analyzed at appropriate times before recording the data.

\section{CELLULAR MORPHOLOGY}

Cells were grown to log-phase as described above, HU (25$200 \mathrm{mM})$ or MMS $(0.033 \% \mathrm{v} / \mathrm{v})$ was added, and cells were incubated for 5 or $22 \mathrm{~h}$ before they were fixed with $3.7 \%$ formaldehyde. Cells were washed with phosphate buffered saline (PBS, $50 \mathrm{mM}, \mathrm{pH} \mathrm{7}$ ) and further suspended in PBS before analyzing them under a Nikon Eclipse (TE2000-5) microscope with a $40 \times / 100 \times$ objective lens.

\section{EFFECT OF HU ON INTRACELLULAR GROWTH OF $\mathrm{Cn}$}

The murine reticulum sarcoma macrophage-like cell line J774A.1 cells were used up to passage \#8. Cells were then plated in 96well cell culture plates in Dulbecco's minimal essential medium supplemented with $10 \%$ fetal bovine serum. WT Cn (H99) and its isc $1 \Delta$ derivative were grown overnight in YPD at $30^{\circ} \mathrm{C}$. Cells were washed three times in PBS and counted. Approximately $10^{5}$ cells in DMEM + FBS medium were added with $10 \mu \mathrm{g} / \mathrm{ml}$ of anti-GXM monoclonal antibody $18 \mathrm{~B} 7$ (kindly provided by Dr. Arturo Casadevall) with $1 \mathrm{mM} \mathrm{HU}$ or without HU. Meanwhile the macrophage-like cells were washed off the non-adhered cells and activated with 50 units $/ \mathrm{ml}$ of recombinant murine gamma interferon (IFN $\gamma$ ) and $0.3 \mu \mathrm{g} / \mathrm{ml}$ of lipopolysaccharide (LPS). The antibody-opsonized $\mathrm{Cn}$ cells were added to the macrophage cells at an effector-to-target ratio of 1:1. After incubation for $2 \mathrm{~h}$, extracellular $\mathrm{Cn}$ cells were washed with three changes of warm DMEM medium and fresh medium without or with $1 \mathrm{mM}$ of HU. For one set of the experiments $200 \mu l$ sterile water was added to each well and the macrophage-like cells were lysed by pipetting several times. The samples were diluted and an aliquot was spread on YPD agar plate for determining colony forming units (CFUs); this set served as the time-point "zero." The other time points were 6,12 , and $24 \mathrm{~h}$, at which points the supernatant was aspirated and cells were rinsed once with DMEM. Macrophage cells were lysed by adding $200 \mu \mathrm{l}$ of sterile water and pipetting several times. The samples were diluted and spread on YPD agar plate for determining the CFUs.

For the phagocytic indices (PI) and for photographs, the conditions were same as above except that the macrophage-like cells were grown on glass cover slips. After $2 \mathrm{~h}$ of the $\mathrm{Cn}$ challenge, the cells were washed three times with PBS, fixed with ice-cold methanol, and stained with Giemsa. For the 24-h experiment, cells were washed three times and fresh medium without $\mathrm{HU}$ or with $1 \mathrm{mM} \mathrm{HU}$ was added and incubated at $37^{\circ} \mathrm{C}$ in $5 \% \mathrm{CO}_{2}$. After $24 \mathrm{~h}$ the cells were washed three times with PBS, fixed with ice-cold methanol, and stained with Giemsa. Photographs were taken using a Zeiss microscope equipped with charged-coupled device camera. Results for 0 and $24 \mathrm{~h}$ time points are shown in the text.

\section{SURVIVAL STUDIES IN MOUSE MODELS}

Mice were anesthetized with a xylazine-ketamine mixture ( $60 \mu \mathrm{l}$, i.p., $5 \mathrm{mg} / \mathrm{kg}$ xylazine, $95 \mathrm{mg} / \mathrm{kg}$ ketamine). All $\mathrm{Cn}$ strains were grown in YPD medium for $16-18 \mathrm{~h}$ at $30^{\circ} \mathrm{C}$. Cells were washed and re-suspended in PBS. Mice were challenged intranasally with $20 \mu \mathrm{l}$ of the inoculum containing $5 \times 10^{5} \mathrm{Cn}$ cells. After $\mathrm{Cn}$ infection, mice were administered $\mathrm{HU}(0.8 \mathrm{mg} / \mathrm{kg}$ every $48 \mathrm{~h})$. Mice were fed ad libitum and monitored twice daily for signs of morbidity or pain or clinical signs suggesting meningoencephalitis. Mice exhibiting any of these signs were immediately sacrificed using $\mathrm{CO}_{2}$ inhalation followed by cervical dislocation. 


\section{STATISTICAL ANALYSIS}

All data were analyzed by standard Student's $t$-test with $P$ values shown in appropriate figures.

\section{RESULTS}

\section{ABSENCE OF ISC1 CAUSES SENSITIVITY TO HU AND MMS IN Cn CELLS}

Cryptococcus neoformans WT and isc1 $\Delta$ cells were analyzed for their response to long-term exposure to HU and MMS. As shown in Figures 1A,B, whereas WT $C n$ cells recovered from HU and MMS stress, isc1 $\Delta$ cells were highly sensitive to both HU and MMS. The HU sensitivity of $C n$ isc1 $\Delta$ cells was almost comparable to that of $S c$ isc1 $\Delta$ cells (Figure 1A). To ensure that the sensitivity to HU and MMS was due to loss of the ISC1 gene, we examined a $C n$ isc1 $\Delta$ strain containing reconstituted ISC1 for HU and MMS tolerance. As shown in Figures 1A,B, the reconstituted strain was resistant to HU and MMS similar to the WT strain, strongly suggesting a role for Cn ISC1 in HU/MMS tolerance. In addition to testing the role of the reconstituted strain for HU and MMS sensitivity, we tested the role of Cn ISC1 in HU tolerance independently: we expressed the Cn ISC1 gene in an Sc isc1 $\Delta$ strain and examined whether the former complemented HU sensitivity. As shown in Figure 1C, whereas the $S c$ WT strain containing a vector showed $\mathrm{HU}$ resistance, its iscl $\Delta$ derivative containing the vector was $H U$ sensitive. In contrast, the $S c$ isc1 $\Delta$ strain expressing either Sc ISC1 or Cn ISC1 (in pYES vector; Henry et al., 2011) showed HU resistance, albeit with minor differences (Figure 1C). All these results show that $C n$ Iscl plays a key role in HU/MMS tolerance.

\section{ABSENCE OF ISC1 AFFECTS CELL MORPHOLOGY AND CELL DIVISION IN Cn CELLS UPON EXPOSURE TO HU AND MMS}

We examined whether Cn ISC1 controls cell division and cellular morphology under HU stress. Cn WT and isc1s cells were grown in the presence of various concentrations of HU in liquid media and cell morphology was analyzed microscopically. As shown in Figures 2A,B, HU did not affect cell division of WT cells at 25-50 mM concentrations; however, the bud size was relatively large compared to the untreated WT cells. At higher concentrations of HU (100-200 mM) some WT cells had defects in cell division resulting in cell chains. In contrast to the WT cells, cell division in isc1s cells was severely inhibited at low HU concentrations $(25-50 \mathrm{mM})$ resulting in cell chains and lawns (Figures 2A,B); a few misshapen cells were also seen (data not shown). These data suggest a synergism between $\mathrm{HU}$ and the absence of ISC1 in inhibiting cell division.

\section{SYNERGISTIC EFFECTS OF HU AND ISC1 DELETION ON MACROPHAGE INFECTION}

One mechanism by which Isc1 protects $C n$ cells against the host immune response is by increasing the resistance to antifungal activity of macrophages by favoring fungal intracellular growth (Shea et al., 2006). HU treatment of macrophages infected by Toxoplasma gondii, Leishmania amazonensis, Trypanosoma cruzi, and L. mexicana has been shown to drastically reduce the number of infected cells (Melo and Beiral, 2003; Martinez-Rojano et al., 2008). Therefore, we tested whether HU would compromise the

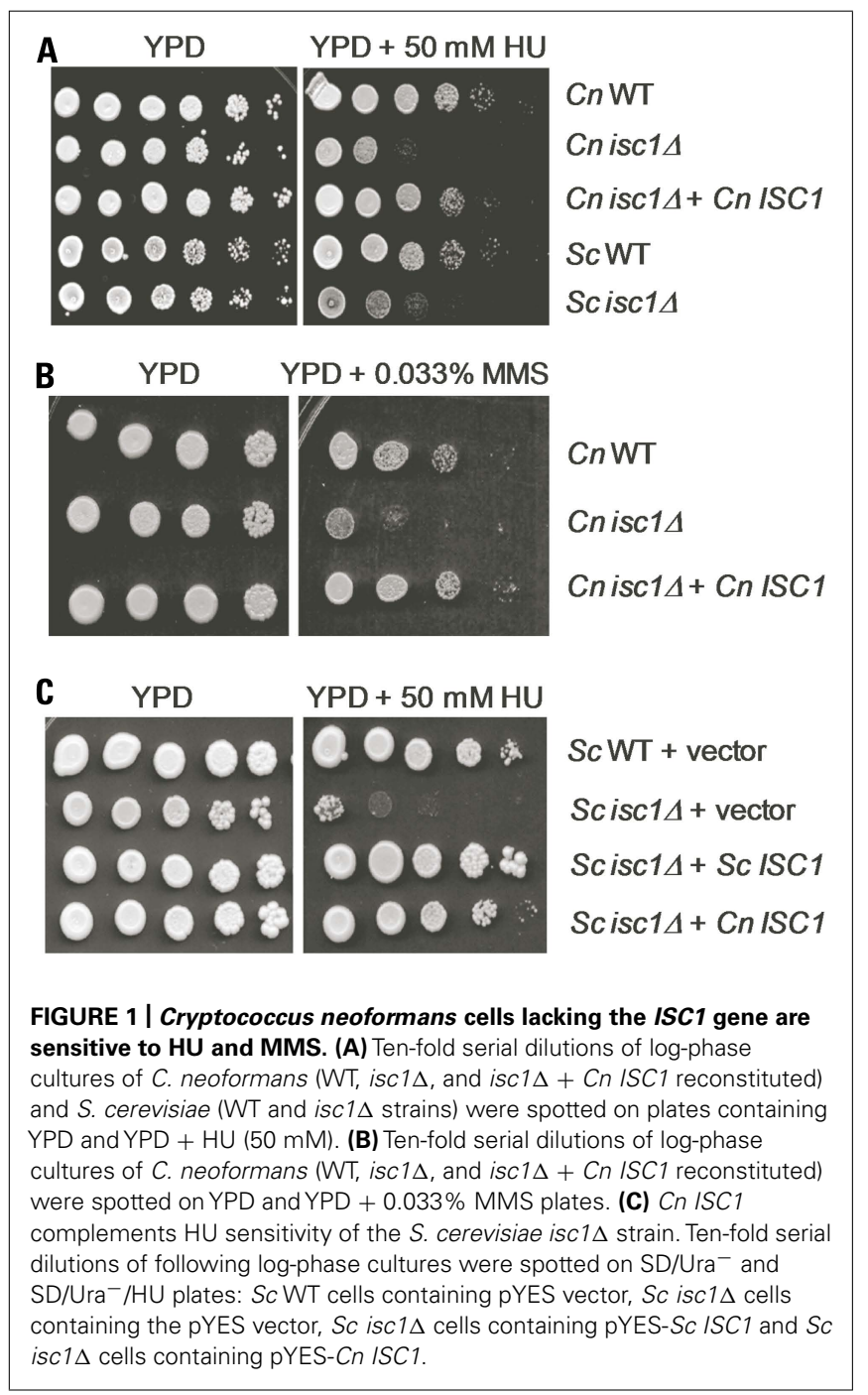

intracellular growth of $C n$ cells. We first allowed macrophages to internalize $C n$ cells and then treated the macrophages with HU. HU treatment diminished the intracellular growth of WT Cn by 3.5-fold (Figure 3A). Interestingly, HU treatment completely abolished the growth of $C n$ isc1 $\Delta$ cells within the macrophages suggesting a strong synergism between $\mathrm{HU}$ and ISC1 deletion. Representative macrophages with $\mathrm{Cn}$ infection are shown in Figure 3B. Importantly, inhibition of intracellular growth was not due to HU's effect on phagocytosis because the drug did not inhibit macrophage ingestion of $\mathrm{Cn}$ (data not shown). We have already demonstrated that a $C n$ iscl $\Delta$ strain reconstituted with $C n$ ISC1 behaves like the WT $C n$ strain in macrophages (Shea etal., 2006). Because the in vitro experiments were carried out at $30^{\circ} \mathrm{C}$ and in vivo experiments were performed at $37^{\circ} \mathrm{C}$, we needed to ensure that the loss of iscl $\Delta$ cell viability in macrophages was not temperature dependent. Thus, we grew WT and isc $1 \Delta$ cells at $37^{\circ} \mathrm{C}$ and compared these data with those obtained at $30^{\circ} \mathrm{C}$. We observed that the growth pattern of WT and isc $1 \Delta$ at $37^{\circ} \mathrm{C}$ was similar to those patterns observed at $30^{\circ} \mathrm{C}$ (data not shown). 


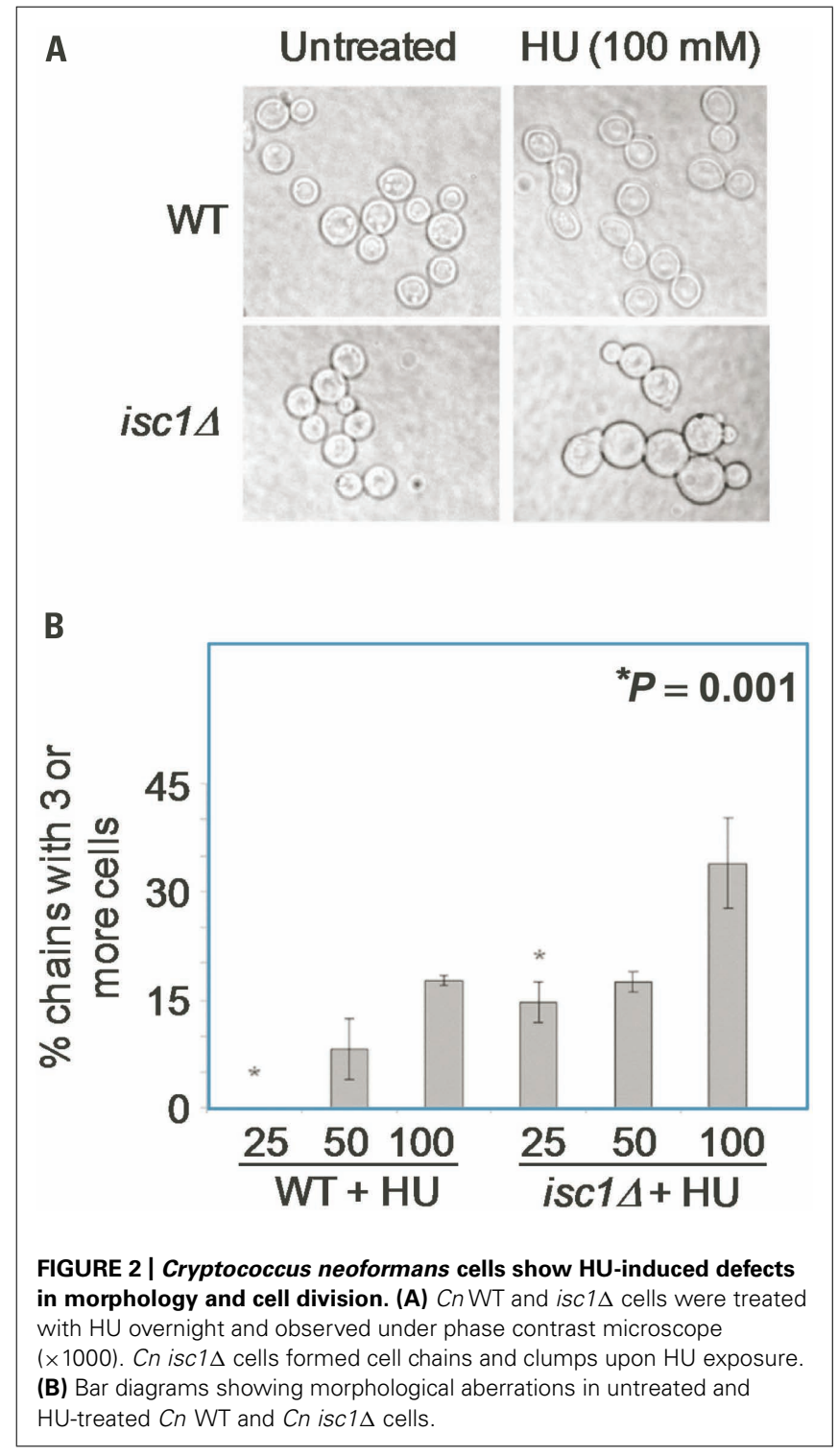

\section{HU TREATMENT INHIBITS GROWTH OF $\mathrm{C} n$ WT AND isc1 $\Delta$ CELLS IN MICE}

We tested the effects of HU on survival and virulence of Cn WT and isc $1 \Delta$ strains in mice. Mice were infected with fungal cells and treated with HU as described in Section "Materials and Methods." Interestingly, $\mathrm{HU}$ inhibited the proliferation of WT Cn cells in mice and significantly prolonged their survival. In addition, we observed that HU acted synergistically when the ISC1 gene was absent to inhibit $C n$ cell growth. We performed survival and tissue burden studies in mice by infecting them intranasally with $C n$ WT or the iscl $\Delta$ strain and then treated the mice with HU ( $0.8 \mathrm{mg} / \mathrm{kg}$ every other day). As expected, untreated mice died within 30 days whereas HU-treated mice survived up to 60 days (Figure 4A). Interestingly, mice infected with $C n$ isc $1 \Delta$ cells also survived for 60 days regardless of $\mathrm{HU}$ treatment (Figure 4B). HU significantly reduced fungal burden, especially in the lung tissue. Specifically, HU-treatment reduced the number of CFUs in the lung infected with $C n$ WT by $\sim 10$-fold from the initial inoculum (Figure 4C). Remarkably the number of $C n$ isc1 $\triangle \mathrm{CFU}$ decreased by $\sim 1,700$ fold in HU-treated mice compared to untreated mice. These data suggest a synergistic effect of HU treatment with ISC1 deletion in increasing host survival by decreasing organ fungal load. The survival of mice infected with WT $C n$ and treated with HU suggests that exposure to HU (at the HU concentration tested) slows down DNA replication and growth of WT cells, allowing the host's immunity to take over the pathogen. The role of Cn ISC1 in mice experiments was revealed by the CFU of HU-treated WT Cn, untreated iscl $\Delta$ and HU-treated iscl $\Delta$ cells recovered from lung tissues.

\section{DISCUSSION}

Our results show that HU slows down growth of WT Cn cells, which helps both mice and macrophages to inhibit further pathogenic growth. This effect is enhanced by deletion of ISC1, suggesting that Isc1 and the sphingolipid metabolic pathway in general should be exploited as novel targets for antifungal drug development, either alone or in combination with existing drugs (e.g., HU) to better control cryptococcosis. Of note, all experiments conducted with mice ended on the 60th day of infection when all surviving mice were sacrificed. Thus, we observed no differences in survival between WT and isc1 $\Delta$ cells upon HU treatment; the isc1 $\Delta$ has a significant defect in virulence. However, treatment with $\mathrm{HU}$ profoundly diminished $\mathrm{Cn}$ proliferation in the lung environment compared to untreated cells.

At present, the molecular mechanism of $\mathrm{HU}$ inhibition of $\mathrm{Cn}$ growth is unknown. We hypothesize that isc1 $\Delta$ may be more susceptible than the WT strain because it controls phytoceramide generation (Garcia etal., 2008) and its decrease in the deletion mutant could affect membrane permeability and thus HU transport. However, this hypothesis was not supported by studies in budding yeast in which the inhibition of DNA synthesis by $\mathrm{HU}$ was not enhanced by deletion of ISC1 (Matmati et al., 2009).

Of note, HU has been shown to have an anti-proliferative activity on T cells (Benito et al., 2007) and to cause neutropenia in humans and mice (Hermans et al., 1999). Because neutropenia is associated with prolonged survival of $\mathrm{Cn}$-infected mice (Mednick et al., 2003) HU could increase mice survival through neutropenia. However, the neutropenic effect of HU is remarkably linked to the administered HU dose. Almost all patients will develop neutropenia when the administered dose is $20-30 \mathrm{mg} / \mathrm{kg} /$ day or greater. However, several studies have shown that such toxicity can be dramatically reduced if the $\mathrm{HU}$ dose is decreased to $4-5 \mathrm{mg} / \mathrm{kg} /$ day. In mice, $\mathrm{HU}$ at $50 \mathrm{mg} / \mathrm{kg} /$ day in a sickle cell model does cause a moderate neutropenia, whereas a lower dose of $25 \mathrm{mg} / \mathrm{kg} /$ day does not cause neutropenia (Lebensburger et al., 2012). The dose used in our mouse experiment was $0.8 \mathrm{mg} / \mathrm{kg} /$ every other day, a dose that is 10 -fold less that the HU dose that does not produce neutropenia in people and 25- to 50-fold less than the dose that does not produce neutropenia in mice. Thus, due to the very low dose of HU used in our experimentations, we hypothesize that the increased mouse survival is not due to an effect of $\mathrm{HU}$ on neutrophils.

We predict that $\mathrm{HU}$ (at the concentration tested here) slows $\mathrm{Cn}$ DNA replication and cell division while host immunity overtakes 


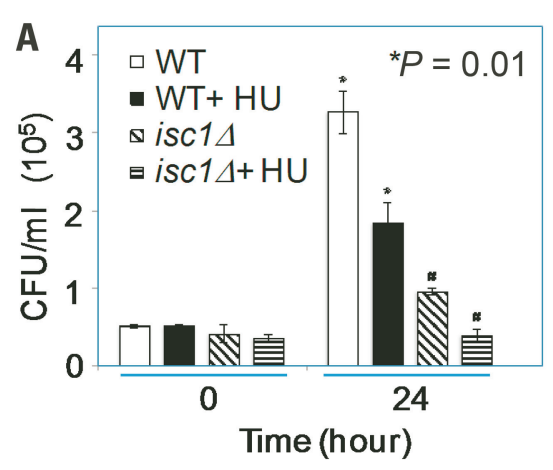

B

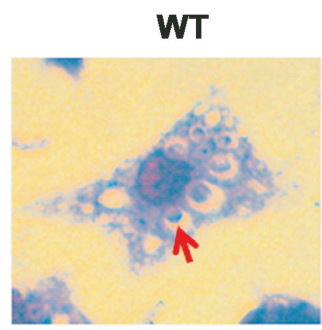

isc1 14

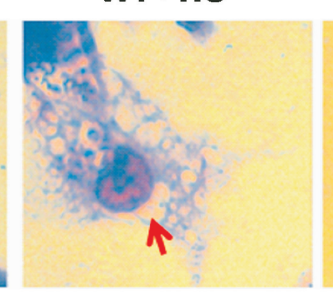

FIGURE 3 | Synergistic role of HU and ISC1 deletion on Cryptococcus infection of the macrophage-like cell line J774A.1. (A) Phagocytosis assay with macrophage-like cell line J774A.1 cells infected with CnWT or isc1 $1 \Delta$ cells in the presence/absence of $\mathrm{HU}$ (see Materials and Methods). (B) $\mathrm{Cn}$ cells phagocytosed by J774A.1 were grown in the presence/absence of HU and stained with Giemsa after $24 \mathrm{~h}$. Photographs were taken with a Zeiss microscope equipped with a CCD camera. All images were captured under oil immersion $(\times 100)$. Red arrows indicate the presence/absence of Cryptococcus in the phagolysosomes of macrophages. Most phagolysosomes in untreated WT cells contained $\mathrm{Cn}$ cells, whereas some HU-treated WT cells still contained $C n$ cells. In contrast, most macrophages did not contain $\mathrm{Cn}$ isc $1 \Delta$ cells regardless of $\mathrm{HU}$ treatment. the pathogen. This effect appears to be enhanced when $C n$ cells are intracellular. This hypothesis is supported by our experiment with macrophage-like cell line showing that HU significantly suppresses fungal cell division within macrophages. Very interestingly, $\mathrm{HU}$ has been tested against various intracellular parasites such as Toxoplasma gondii, L. amazonensis, Trypanosoma cruzi, and L. mexicana (Melo and Beiral, 2003; Martinez-Rojano et al., 2008). Not only did HU induce morphological changes in these parasites, but also it inhibited intracellular multiplication of these microbes, similar to the phenotype observed with $C n$ in macrophages illustrated in this paper. In addition, in L. mexicana HU induced cell cycle arrest suggesting that the mechanism by which HU inhibits the synthesis of the DNA replication and cell division has been maintained in different microbial species.

A recent study points to an important aspect concerning the use of HU to control cryptococcosis. The authors found that HU enhances post-fusion hyphal extension in $\mathrm{Cn}$ cells, but not in haploid cells (Zulkifli et al., 2012). HU is known to induce morphological changes such as hyphal generation in Candida albicans (Shi et al., 2007; Sun etal., 2011) but in Sc it generates limited morphological aberrations (in 1-3\% cells) and extensive morphological aberrations are seen in $S c$ mutants on checkpoint, budding and, notably, in the isc1 $\Delta$ deletion mutant (Jiang and Kang, 2003; Enserink et al., 2006; Tripathi et al., 2011). It seems that $C n$ behaves similar to $S c$; morphological changes by HU (at low concentrations) only occur in isc1 $\Delta$ cells and not in WT cells. In another study it has been shown that certain $C n$ mutants such as ras1 $\Delta$ were sensitive to HU and MMS (Maeng et al., 2010).
Intriguingly, the morphological changes ascribed to HU are strictly linked to defects in yeast cell division. Possibly, in addition to the inhibition of DNA synthesis, HU also affects actin polymerization/depolymerization during $C n$ cell division and cell wall synthesis (Enserink et al., 2006; Tripathi et al., 2011). This hypothesis is supported by our previous studies in $S c$ in which we showed that actin depolymerization is inhibited by HU especially in conditions in which ISC1 is deleted. This will ultimately block cell division or cell proliferation (Tripathi et al., 2011), possibly through the regulation of morphogenesis and DNA integrity checkpoint proteins. The latter hypothesis is also supported by the results presented in this paper in which we show that HU delays the separation of $\mathrm{Cn}$ isc1 $\Delta$ daughter cells from the mother cell (Figures 2A,B). This delay in cell division of $C n$ cells may expose the isc1 $\Delta$ cells for longer time to intracellular inhibitors (e.g., hydrogen peroxide, nitric oxide) rendering isc1 $\Delta$ even more susceptible to the intracellular compared to the extracellular environment. Considering that the $C n$ isc1 $\Delta$ is already hypersusceptible to hydrogen peroxide and nitric oxide (Shea et al., 2006), the treatment with HU may render the isc1 $\Delta$ cells even more sensitive than WT cells. Thus, it is possible that HU does increase the killing capacity of macrophages indirectly by increasing the exposure of undivided $C n$ cells to intracellular toxins. Finally, in Sc HU affects chitin deposition on the cell wall (Tripathi et al., 2011) particularly when ISC1 is deleted. This observation further supports a role for Isc1 under HU stress in cell division as chitin is an important regulator of cell morphology and cell division in yeasts 

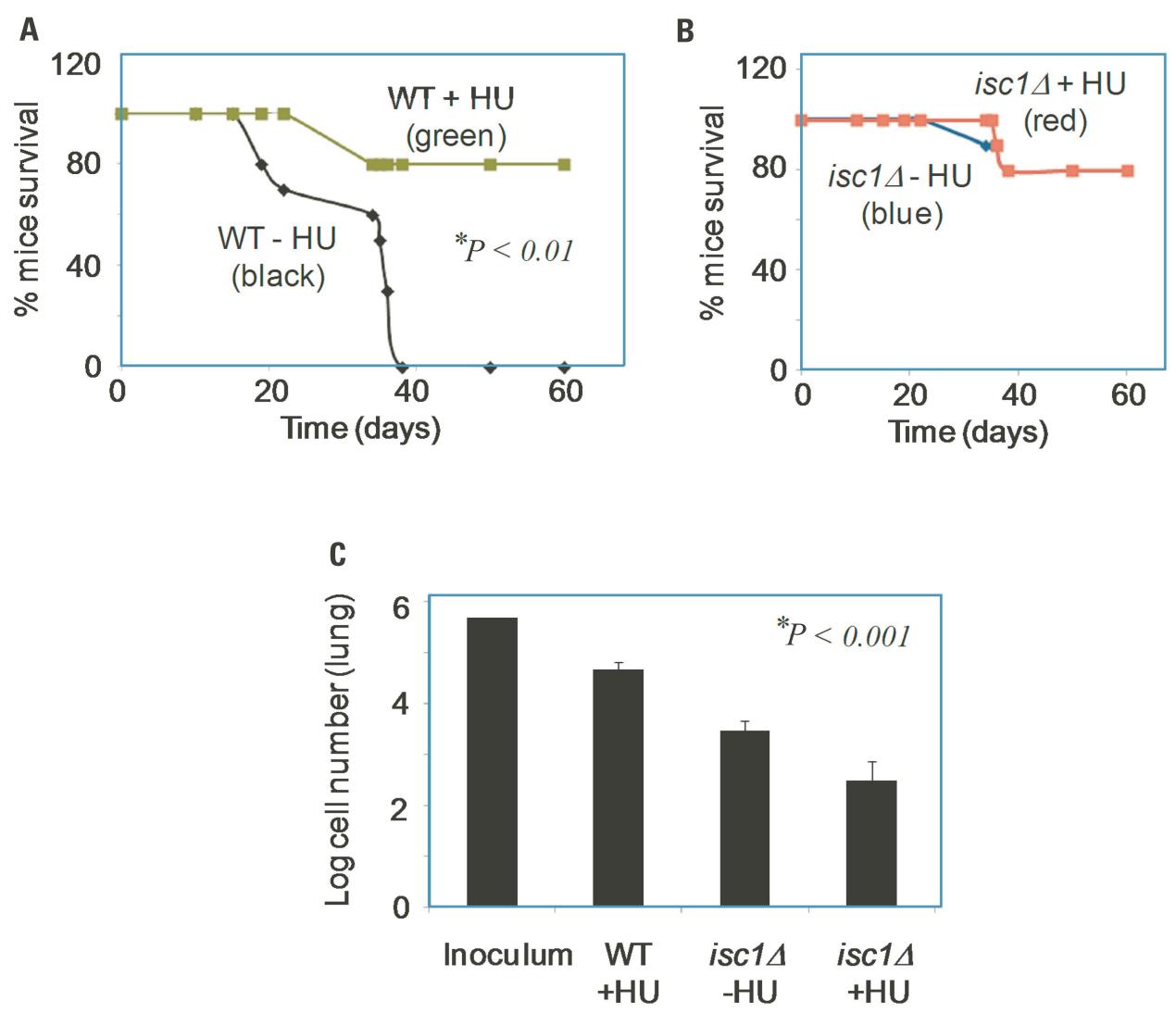

FIGURE 4 | Role of HU and ISC1 deletion on the survival of mice and on lung tissue burden. (A) Survival curve of CBA/J mice upon infection with WT $\mathrm{Cn}$ in the presence (green) or absence (black) of $\mathrm{HU}$; (B) Survival curve of CBA/J mice upon infection with $\mathrm{Cn}$ isc1 $1 \Delta$ cells in the presence (red) or absence (blue) of HU. (C) Survival of $C$ cells in lung tissue of CBA/J mice after 60 days of infection. Lung tissues were collected from mice and Cn CFU was counted by plating on YPD plates.

(Roh et al., 2002). These are exciting possibilities that we will explore in the future.

\section{ACKNOWLEDGMENTS}

We thank Aimee Guillotte in Del Poeta's laboratory for helping with the animal experiments. We thank Dr. Jennifer Schnellmann and Dr. Ashley Cowart for editing the manuscript. This work was performed in part by the National Institute of Health (NIH) awards AI056168, AI071142, AI078493, and AI087541 to Maurizio Del Poeta and, in part, by pilot research funding from an American Cancer Society Institutional Research Grant

\section{REFERENCES}

Alcasabas, A. A., Osborn, A. J., Bachant, J., Hu, F., Werler, P. J., Bousset, K., Furuya, K., Diffley, J. F., Carr, A. M., and Elledge, S. J. (2001). Mrcl transduces signals of DNA replication stress to activate Rad53. Nat. Cell Biol. 3, 958-965.

Bando, M., Katou, Y., Komata, M., Tanaka, H., Itoh, T., Sutani, T., and Shirahige, K. (2009). Csm3, Tof1, and $\mathrm{Mrcl}$ form a heterotrimeric mediator complex that associates with DNA replication forks. J. Biol. Chem. 284, 34355-34365.

Benito, J. M., Lopez, M., Lozano, S., Ballesteros, C., Gonzalez-Lahoz, J., and Soriano, V. (2007). Hydroxyurea exerts an anti-proliferative effect on $\mathrm{T}$ cells but has no direct impact on cellular activation. Clin. Exp. Immunol. 149, 171-177.

Chang, M., Bellaoui, M., Boone, C., and Brown, G. W. (2002). A genome-wide screen for methyl methanesulfonate-sensitive mutants

(ACS-IRG\# 97-219-08) awarded to the Hollings Cancer Center, Medical University of South Carolina, and in part by a Center of Biological Research Excellence (COBRE P20 RR17677) pilot grant to Bidyut K. Mohanty. Kaushlendra Tripathi is thankful to the American Society for Biochemistry and Molecular Biology (ASBMB) for a travel award. This work was conducted in a facility constructed with support from the NIH C06 RR015455 from the Extramural Research Facilities Program of the National Center for Research Resources. Maurizio Del Poeta is a Burroughs Welcome New Investigator in the Pathogenesis of Infectious Diseases.

reveals genes required for $S$ phase progression in the presence of DNA damage. Proc. Natl. Acad. Sci. U.S.A. 99, 16934-16939.

Dadachova, E., and Casadevall, A. (2011). Cryptococcus neoformans as a model for radioimmunotherapy of infections. Interdiscip. Perspect. Infect. Dis. 2011, 830286.

Del Poeta, M., and Casadevall, A. (2011). Ten challenges on Cryptococcus and cryptococcosis. Mycopathologia 173, 303-310.
Enserink, J. M., Smolka, M. B., Zhou, H., and Kolodner, R. D. (2006). Checkpoint proteins control morphogenetic events during DNA replication stress in Saccharomyces cerevisiae. J. Cell Biol. 175, 729-741.

Feldmesser, M., Kress, Y., Novikoff, P., and Casadevall, A. (2000). Cryptococcus neoformans is a facultative intracellular pathogen in murine pulmonary infection. Infect. Immun. 68, 4225-4237. 
Garcia, J., Shea, J., Alvarez-Vasquez, F., Qureshi, A., Luberto, C., Voit, E. O., and Del Poeta, M. (2008). Mathematical modeling of pathogenicity of Cryptococcus neoformans. Mol. Syst. Biol. 4, 183.

Goldman, D. L., Lee, S. C., Mednick, A. J., Montella, L., and Casadevall, A. (2000). Persistent Cryptococcus neoformans pulmonary infection in the rat is associated with intracellular parasitism, decreased inducible nitric oxide synthase expression, and altered antibody responsiveness to cryptococcal polysaccharide. Infect. Immun. 68, 832-838.

Hartman, J. L. IV, and Tippery, N. P. (2004). Systematic quantification of gene interactions by phenotypic array analysis. Genome Biol. 5, R49.

Henry, J., Guillotte, A., Luberto, C., and Del Poeta, M. (2011). Characterization of inositol phosphosphingolipid-phospholipase C 1 (Iscl) in Cryptococcus neoformans reveals unique biochemical features. FEBS Lett. 585, 635-640.

Hermans, P., De Wit, S., Sommereijns, B., O'Doherty, E., and Clumeck, N. (1999). Use of hydroxyurea in heavily pretreated patients with HIV infection. Antivir. Ther. 4(Suppl. 3), 19-22.

Idnurm, A., Bahn, Y. S., Nielsen, K., Lin, X., Fraser, J. A., and Heitman, J. (2005). Deciphering the model pathogenic fungus Cryptococcus neoformans. Nat. Rev. Microbiol. 3, 753-764.

Jarvis, J. N., Dromer, F., Harrison, T. S., and Lortholary, O. (2008). Managing cryptococcosis in the immunocompromised host. Curr. Opin. Infect. Dis. 21, 596-603.

Jiang, Y. W., and Kang, C. M. (2003). Induction of S. cerevisiae filamentous differentiation by slowed DNA synthesis involves Mec1, Rad53 and Swe1 checkpoint proteins. Mol. Biol. Cell 14, 5116-5124.

Katou, Y., Kanoh, Y., Bando, M., Noguchi, H., Tanaka, H., Ashikari, T., Sugimoto, K., and Shirahige, K. (2003). S-phase checkpoint proteins Tofl and Mrcl form a stable replication-pausing complex. Nature 424, 1078-1083.

Kovacic, P. (2011). Hydroxyurea (therapeutics and mechanism): metabolism, carbamoyl nitroso, nitroxyl, radicals, cell signaling and clinical applications. Med. Hypotheses 76, 24-31.

Kozubowski, L., and Heitman, J. (2012). Profiling a killer, the development of Cryptococcus neoformans. FEMS Microbiol. Rev. 36, 78-94.

Kronstad, J. W., Attarian, R., Cadieux, B., Choi, J., D'Souza, C. A., Griffiths, E. J., Geddes, J. M., Hu, G., Jung, W. H., Kretschmer, M., Saikia, S., and Wang, J. (2011). Expanding fungal pathogenesis: Cryptococcus breaks out of the opportunistic box. Nat. Rev. Microbiol. 9, 193-203.

Lebensburger, J. D., Pestina, T. I., Ware, R. E., Boyd, K. L., and Persons, D. A. (2012). Hydroxyurea therapy requires $\mathrm{HbF}$ induction for clinical benefit in a sickle cell mouse model. Haematologica 95, 1599-1603.

Levitz, S. M. (2001). Cryptococcus neoformans: intracellular or extracellular? Trends Microbiol. 9, 417-418.

Maeng, S., Ko, Y. J., Kim, G. B., Jung, K. W., Floyd, A., Heitman, J., and Bahn, Y. S. (2010). Comparative transcriptome analysis reveals novel roles of the Ras and cyclic AMP signaling pathways in environmental stress response and antifungal drug sensitivity in Cryptococcus neoformans. Eukaryot. Cell 9, 360-378.

Martinez-Rojano, H., MancillaRamirez, J., Quinonez-Diaz, L., and Galindo-Sevilla, N. (2008). Activity of hydroxyurea against Leishmania mexicana. Antimicrob. Agents Chemother. 52, 3642-3647.

Matmati, N., Kitagaki, H., Montefusco, D., Mohanty, B. K., and Hannun, Y. A. (2009). Hydroxyurea sensitivity reveals a role for ISC1 in the regulation of G2/M. J. Biol. Chem. 284, 8241-8246.

Mednick, A. J., Feldmesser, M., Rivera, J., and Casadevall, A. (2003). Neutropenia alters lung cytokine production in mice and reduces their susceptibility to pulmonary cryptococcosis. Eur. J. Immunol. 33, 1744-1753.

Melo, E. J., and Beiral, H. J. (2003). Effect of hydroxyurea on the intracellular multiplication of Toxoplasma gondii, Leishmania amazonensis and Trypanosoma cruzi. Braz. J. Med. Biol. Res. 36, 65-69.

Morschhauser, J. (2010). Regulation of multidrug resistance in pathogenic fungi. Fungal Genet. Biol. 47, 94-106. Park, B. J., Wannemuehler, K. A., Marston, B. J., Govender, N., Pappas, P. G., and Chiller, T. M. (2009). Estimation of the current global burden of cryptococcal meningitis among persons living with HIV/AIDS. AIDS 23, 525-530.

Parsons, A. B., Brost, R. L., Ding, H., Li, Z., Zhang, C., Sheikh, B., Brown, G. W., Kane, P. M., Hughes,
T. R., and Boone, C. (2004). Integration of chemical-genetic and genetic interaction data links bioactive compounds to cellular target pathways. Nat. Biotechnol. 22, 62-69.

Rhome, R., and Del Poeta, M. (2010). Sphingolipid signaling in fungal pathogens. Adv. Exp. Med. Biol. 688, 232-237.

Roh, D. H., Bowers, B., Schmidt, M., and Cabib, E. (2002). The septation apparatus, an autonomous system in budding yeast. Mol. Biol. Cell 13, 2747-2759.

Sawai, H., Okamoto, Y., Luberto, C., Mao, C., Bielawska, A., Domae, N., and Hannun, Y. A. (2000). Identification of ISC1 (YER019w) as inositol phosphosphingolipid phospholipase C in Saccharomyces cerevisiae. J. Biol. Chem. 275, 39793-39798.

Shea, J. M., and Del Poeta, M. (2006). Lipid signaling in pathogenic fungi. Curr. Opin. Microbiol. 9, 352-358.

Shea, J. M., Kechichian, T. B., Luberto C., and Del Poeta, M. (2006). The cryptococcal enzyme inositol phosphosphingolipid-phospholipase $\mathrm{C}$ confers resistance to the antifungal effects of macrophages and promotes fungal dissemination to the central nervous system. Infect. Immun. 74, 5977-5988.

Shi, Q. M., Wang, Y. M., Zheng, X. D., Lee, R. T., and Wang, Y. (2007). Critical role of DNA checkpoints in mediating genotoxic-stress-induced filamentous growth in Candida albicans. Mol. Biol. Cell 18, 815-826.

Singh, A., and Del Poeta, M. (2011). Lipid signalling in pathogenic fungi. Cell. Microbiol. 13, 177-185.

Steenbergen, J. N., Shuman, H. A., and Casadevall, A. (2001). Cryptococcus neoformans interactions with amoebae suggest an explanation for its virulence and intracellular pathogenic strategy in macrophages. Proc. Natl. Acad. Sci. U.S.A. 98, 15245-15250.

Sun, L. L., Li, W. J., Wang, H. T., Chen, J., Deng, P., Wang, Y., and Sang, J. L. (2011). Protein phosphatase Pph3 and its regulatory subunit Psy2 regulate Rad53 dephosphorylation and cell morphogenesis during recovery from DNA damage in Candida albicans. Eukaryot. Cell 10, 1565-1573.

Tripathi, K., Matmati, N., Zheng, W. J., Hannun, Y. A., and Mohanty, B. K. (2011). Cellular morphogenesis under stress is influenced by the sphingolipid pathway gene ISC1 and DNA integrity checkpoint genes in Saccharomyces cerevisiae. Genetics 189, 533-547.
Warkentien, T., and Crum-Cianflone, N. F. (2010). An update on Cryptococcus among HIV-infected patients. Int. J. STD AIDS 21, 679-684.

Woolstencroft, R. N., Beilharz, T. H., Cook, M. A., Preiss, T., Durocher, D., and Tyers, M. (2006). Ccr4 contributes to tolerance of replication stress through control of CRT1 mRNA poly(A) tail length. J. Cell Sci. 119, 5178-5192.

Zaragoza, O., Garcia-Rodas, R., Nosanchuk, J. D., Cuenca-Estrella, M., Rodriguez-Tudela, J. L., and Casadevall, A. (2010). Fungal cell gigantism during mammalian infection. PLoS Pathog. 6, e1000945. doi: 10.1371/journal.ppat.1000945

Zegerman, P., and Diffley, J. F. (2003). Lessons in how to hold a fork. Nat. Struct. Biol. 10, 778-779.

Zhang, O., Wilson, M. C., Xu, W., Hsu, F. F., Turk, J., Kuhlmann, F. M., Wang, Y., Soong, L., Key, P., Beverley, S. M., and Zhang, K. (2009). Degradation of host sphingomyelin is essential for Leishmania virulence. PLoS Pathog. 5, e1000692. doi: 10.1371/journal.ppat. 1000692

Zulkifli, M. N., Kaur, J. N., and Panepinto, J. C. (2012). Hydroxyurea enhances post-fusion hyphal extension during sexual development in $C$. neoformans var. grubii. Mycopathologia 173, 113-119.

Conflict of Interest Statement: The authors declare that the research was conducted in the absence of any commercial or financial relationships that could be construed as a potential conflict of interest.

Received: 11 April 2012; accepted: 08 May 2012; published online: 24 May 2012.

Citation: Tripathi $K$, Mor V, Bairwa $N K$, Del Poeta $M$ and Mohanty BK (2012) Hydroxyurea treatment inhibits proliferation of Cryptococcus neoformans in mice. Front. Microbio. 3:187. doi: 10.3389/fmicb.2012.00187

This article was submitted to Frontiers in Fungi and Their Interactions, a specialty of Frontiers in Microbiology.

Copyright $\odot 2012$ Tripathi, Mor, Bairwa, Del Poeta and Mohanty. This is an open-access article distributed under the terms of the Creative Commons Attribution Non Commercial License, which permits non-commercial use, distribution, and reproduction in other forums, provided the original authors and source are credited. 